\title{
Human-Animal Studies: Remembering the Past, Celebrating the Present, Troubling the Future
}

\author{
Kenneth Shapiro \\ Animals and Society Institute, Ann Arbor, MI \\ ken.shapiro@animalsandsociety.org
}

\begin{abstract}
This is the third in a series of reports on the state of the field of Human-Animal Studies. In the introductory section, major terms in the prevailing definition of the fieldHuman-Animal Studies is the interdisciplinary study of human-animal relationshipsare unpacked and critically analyzed. Subsequent sections deal with the field's past, present, and possible futures. A schematic history of the field considers both scholarly contributions and programmatic inroads in the academy. The current state of the field section describes its breadth in terms of publication venues, disciplines that interface with it, and the variety of methods employed. It also offers a description of several common strategies that critique the received view of the categorical divide between human and other animal beings. The final section highlights both the potential of and anticipated roadblocks to each of several future trajectories.
\end{abstract}

\section{Keywords}

human-animal studies - human-animal relationships - animal studies - critical animal studies - anthrozoology - animal protection movement - interdisciplinarity - history

\section{Introduction}

This latest in a series of papers on the state of the field of Human-Animal Studies (HAS; Shapiro, 2002a; Shapiro \& DeMello, 2010) addresses several questions: Where did the field come from, how did it get to where it is, and where is it going? It places particular emphasis on shifts, trends, tensions, and future trajectories. 
Among the many contexts that have influenced and will continue to influence the state of the field are (1) the nonhuman animal rights, the environmental, and the feminist social justice movements; (2) the Anthropocene and global warming; (3) the rise of intensive animal farming and the worldwide decline in the populations of wildlife; $(4)$ the global turn to the political right and the dominance of neo-liberalism; and (5) the perennial separation of the humanities and the sciences. In this brief paper, I can only note these large forces.

To accommodate the two intended audiences of the paper, new and established HAS scholars, the paper begins with a discussion of the definition and scope of the field and a sketch of its history, and then moves to a consideration of more nuanced theoretical and methodological issues. The final section presents speculations about possible future trajectories of the field and the barriers and pitfalls each is likely to face.

By way of disclosure of my own perspectives and, no doubt, biases, my primary training and early career was in clinical and personality psychology with an interest in psychodynamic and experiential approaches to therapy and in qualitative research methods, particularly, the methods developed in phenomenological psychology. My undergraduate degree was in intellectual history and I continued throughout my career to be interested in the history of ideas. In the early 80 , I became an animal advocate, focusing on the critique of the use of animal models for the understanding of human psychology. I subsequently became engaged in the development of the field of HAS, founding two journals (this journal and the Journal of Applied Animal Welfare Science).

\section{Literature Review}

While many papers comment on the state of the field either explicitly or implicitly, I limit this literature review to consideration of articles that present a general overview of the field. I also note examples of articles that review the state of a particular discipline interfacing with HAS and those key articles published under one of the other names of the field (some of which claim to be a distinct field).

Although now dated, the 1oth anniversary issue of the launch of Society \& Animals (S\&A; Shapiro, 2002b) presents an overview of the field and articles on several disciplines interfacing with the field (psychology, sociology, criminology, anthropology, political science, history, geography, post-colonial studies, feminism, and economics). Published shortly thereafter, the 25th anniversary 
issue of Anthrozoös (2012) presents articles on several interfacing disciplines (history, visual arts, literary criticism, and sociology). Other overall views of the field include: Waldau's Animal Studies: An Introduction (2013); Taylor's Humans, Animals, and Society: An Introduction to Human-Animal Studies (2013); and Marvin and McHugh's Routledge Handbook of Human-Animal Studies (2014).

DeMello's edited volume Teaching the Animal: Human-Animal Studies Across the Disciplines (2010) provides assessments of the field organized by interfacing disciplines. Fudge (2017) does the same for the field of history, and Dhont, Hodson, Loughnan, and Amiot (2019) for social psychology. Echeverri, Karp, Naidoo, Zhao, and Chan (2018) focus on methodological issues at the interface of HAS and conservation biology. McCance (2012) presents an overview of the field under the rubric of Critical Animal Studies.

\section{Definition}

Despite the oft-cited proliferation of (contending) names, the following general definition of the field is largely consensual: HAS is the interdisciplinary study of human-animal relationships (HAR). The two earliest journals, Anthrozoös in 1988 and $S \& A$ in 1993, and the first journal devoted to studies in the humanities, Humanimalia in 2010, all defined the field in these terms. Other journals limited the definition to certain areas of HAR-for example, the several journals on animal-related law and the Journal of Animal Ethics in 2011 on the "moral dimensions of our relations with animals."

As is the case in many fields, the definition refers to a certain subject matter. Unlike most traditional disciplines-for example, experimentalism in psychology, ethnography in anthropology, one or another hermeneutic in literary studies-because of its interdisciplinarity, HAS is not limited to a primary method.

However, while varied in methods employed, scholars in the field generally share a common approach to the subject matter. The HAS approach keys in on the presence and influence of nonhuman animals (hereafter, animals) as a way of looking at and understanding the world. It is a critical stance that explicates and evaluates how animals figure in our understanding and treatment of them, and their influence on us and on the world. Much as women's studies and environmental studies rest, respectively, on the value of women and the environment, the critical stance of HAS scholars explicates and evaluates the objects of its study, HAR, in ethical terms-particularly on the value of valuing animals for themselves. 


\section{Scope}

At first glance, the study of HAR would seem to severely limit the scope of the field. However, the fecundity of evolution in producing millions of species of animals and the ingenuity of humans in genetically and socially constructing animals and, it follows, forms of HAR, has produced and is continuing to produce a rich and extensive field. As to the former, while the rate of humangenerated species' extinctions is accelerating (Kolbert, 2016), it is generally believed that we have not yet identified and described several million of the estimated 8.7 million existing species (EarthSky, 2011). Regarding HAR largely constructed by humans, we are continually forming new relationships-for example, animal-assisted therapy, genetically engineered hybrids or chimeras. As we construct more relationships, we increase the scope of the field and provide further forms of HAR as grist for the investigatory mill. Far from being limited, the power of evolution and social and technologically based construction ensures the open-ended expansion of the scope of the field.

To further clarify the definition and scope of the field, I critically examine the primary terms in the definition.

\section{"Relationships"}

Relationships occupy a space between two entities. While anchored in and coconstituted by two distinct entities which it, in turn, modifies, a relationship is a distinct phenomenon. While a full description of any two entities can furnish the limits and potential forms of their relationship, it is not yet a description of that relationship. This distinction may be self-evident but it is one not always respected in practice.

Equally self-evident is the distinction between "relationship" and "relation." Apples and bananas are related as they have many similar properties- they are both fruits and both mix well in my smoothie; but this similarity and this mixing does not constitute a relationship. The tasteful and nutritious mixture is not a form of attachment or bonding or intentional connectedness or interaction. In fact, even a cursory description of their similarities and differences reveals that apples and bananas are entities incapable of forming a relationship. (Note, however, the attribution of "actant" to inanimate entities, to be discussed further below [Latour, 2007], and the emerging conversation about whether advances in artificial intelligence will produce entities capable of forming a relationship with humans [Lin, 2016]).

The emphasis on relationships, the between, in the definition of HAs can be understood historically. For it offers a corrective to scholarship both in human-centered studies and nonhuman animal-centered studies that give 
little attention to HAR. On the animal side, these pre-HAs fields included animal behavior in psychology, ethology in zoology, and "animal studies" in biomedicine - the latter of which referred to studies of nonhuman animals as "models," vehicles for the understanding of humans. (For this reason, at least in the first decades, it was problematic to encumber the emerging study of HAR with the handle "animal studies." A Google search verifies that this is still a major usage of the term.) On the human side, the disciplines in social sciences and humanities were heavily human-centered, as many of their names suggest—anthropology, humanities.

Although not explicitly proffered as alternatives to "relationship," two terms might be so nominated. "Entanglement" is a characteristic of many if not most HAR and refers to their complexity. That complexity may be a result of its history as relationships are shaped by their institutional and linguistic provenances; or it may be bodily, as the two entities are hybrids, literarily entwined in each other (Haraway, 2007). To understand a relationship is, then, to disentangle it.

A second term "interaction" is preferred in disciplines that traditionally restrict study to phenomena that are directly observable. For disciplines such as the quantitative social sciences, relationship consists of interaction where that is fully exhausted and constrained by the observed behavior between two entities. Relationship as an emergent space between two entities that has a particular form and a concomitant experience by the two parties to it is, in this rendering, beyond the data and therefore both suspect and unnecessary.

To conclude this subsection, I discuss some advantages and challenges attendant to the focus on relationships. As noted, an advantage is the richness and open-endedness of the scope of the field. Another is the extensive range of possible relationships. To suggest its extent, consider this sampling: present or historical, real or imagined, loving or hateful, one-way or reciprocal, engaged or indifferent, personal or impersonal, beneficial or harmful, dominant and subordinate, oppressor and oppressed.

That most relationships are to some degree co-constituted assures consideration of the perspectives of both entities in even the most one-sidedly exploitative and objectifying instances. Starting from this point offers a corrective to the anthropocentrism of traditional social science and humanities. However unequal the power differences in a relationship, this means that the animals involved have at least some level of agency. In turn, this implies that both parties are co-responsible for the impact of the relationship on the other party. This fore-fronts an important feature of the critical stance of HAS scholars: the explication of the ethics underlying or embodied in any HAR. 
On the liabilities side, the study of a relationship is more difficult methodologically, as it requires knowledge of two distinct entities. In the case of HAR, an additional challenge is that the individuals are members of different species, each of which may require their own methods of access.

Another barrier or burden is that, while co-constituted by both the human and animal parties, the forms of our relationships with other animals are more heavily influenced by the former, as most HAR are complex products of our construction. Even when we are including the animal side of an HAR, we can "lose" the actual animals in the dense layers of our constructions of them. I deal below with the problematic of what, if anything, is beyond or beneath the constructed animal.

A final disadvantage is the apparent exclusion of aggregates in this definition, as we typically think of a relationship as involving two individuals. But clearly studies of species, populations, and generations directly impact, and are instantiated in, a given one-on-one relationship. Uncovering or recovering the nature and/or construction of these aggregations is part of the task of understanding a target relationship.

\section{"Human-Animal"}

As many scholars have (frettingly) pointed out, this conjunction of the terms "human" and "animal" is a serious issue (Shapiro, 2002a), as humans are a subcategory of animal. This is a problem for several of the various current names of the field-HAs, Anthrozoology, Animal Studies, Critical Animal Studies, and Human-Animal Interactions. The problem is exacerbated by the fact that, historically, the rationale, usually unstated, for committing this categorical error was to enable the use of animals as a foil for understanding human beings - it was contended that unlike other animals, humans have unique capabilities, such as agency, culture, reflection, and language.

Unfortunately, there is as yet no accepted solution to this usage that does not valorize humans - although see Kemmerer's (2006) suggestion. More subtly, the very emergence of a field studying HAR inevitably privileges the human, as it features one species' relationships with a multitude of other species.

Putting aside the question of appropriate terminology, a more substantive issue is whether to include in the scope of the field studies of animals that make no pretense to include humans or HAR. Some have argued that their inclusion is justified as a corrective, a kind of affirmative action, to the greater attention given historically to human-centered studies and, as well, to studies of animals whose primary intent is to model human being. Ironically, as noted earlier, the very heart of the HAS project is to provide that corrective. 
Clearly, fields that exclusively study animals can provide foundations for HAR but should be considered as "related" or adjunct fields much as chemistry is a related field to biology. However, studies that include discussion of the implications of their findings for the possible forms of HAR are an exception and are often published in HAS-devoted journals.

Two trends in the natural science literature on animals are expanding the scope of the field: the study of cross-species relationships, both animal-animal and human-animal, and the tendency in ethology and comparative psychology to address the ethical and policy implications of findings. An example of the former is the recent development of cross-species ethnography (Kopnina, 2017). An example of the latter is the emergent field of animal welfare science, which is devoted to the study of assessing the impact of our treatment of the welfare of animals in various settings. These studies describe existing HAR, provide controlled experiments comparing current to less distressing or injurious practices, and, accordingly, recommend changes in policies and practices.

Finally, consider the status of studies of HAR that only present the human side of a HAR and those uncritically presenting HAR that clearly degrade the animal side of the relationship. Regarding the former, studies of animalassisted therapy and activities often do not address the impact of such activities on the animals involved. Fortunately, this issue is being addressed in more recent studies (Glenk, Kothgassner, Stetina, Palmer, Kepplinger, \& Baran, 2014). Regarding the latter, as noted earlier, ideally HAs brings an approach to studies involving animals that explicates and critically evaluates both entities in the relationship. Researchers that do not provide that should be encouraged to do so.

\section{"Interdisciplinary"}

Many fields interface with HAS. In her seminal volume on HAS published in 2010, DeMello included 12 fields (DeMello, 2010). In my most recent presentation on the field (University of Western Cape, 2019), I indicated that the number of fields interfacing HAS doubled to 24 in that time.

In addition to contributing to the literature on HAS, many of these interdisciplinary fields now have a core of scholars whose primary research project is the study of HAR. Further, many of these fields have developed interest groups within their respective primary disciplines devoted to furthering HAS research and, in some cases, including explicitly the goal of affecting practices and policies involving our treatment of animals. However, this interfacing between HAS and another field is often interdisciplinary in the limited sense that while scholars may contextualize their research within the literature of HAS, in terms 
of substance and method, the study remains firmly ensconced within their home discipline.

We can distinguish this weak version of interdisciplinarity (more properly referred to as multi-disciplinarity) from studies which draw on and integrate the substance, problematics, and/or methods of two distinct fields. This strong form of interdisciplinarity is demanded by the fact that while most mainstream fields traditionally have dealt with either humans or animals, HAS generally requires expertise about both humans and animals. As I will discuss in the history section, failure to meet this demand can result in studies that explicate HAR largely in human-centered terms. This is understandable, as by training scholars are experts in one side of HAR but not both sides.

Clearly the study of relationships between both humans and animals is a significant demand and, increasingly, is being resolved by collaborations between a scholar from a human-centered discipline and one from an animal-centered discipline. As mentioned, some fields are formally recognizing this demand by establishing subspecialties within their home disciplines that explicitly create an amalgam of a human and an animal domain-for example, cross-species ethnography, green criminology, social zooarchaeology. In this way, a related field can become an interdisciplinary field, much as chemistry and physics as related fields to biology gave rise to biochemistry and biophysics. (For a discussion of barriers to interdisciplinarity in the context of cross-species ethnography, see Hamilton \& Taylor, 2017).

\section{Remembering the Past}

As I am not a professional historian and am analyzing the recent past, the following history is necessarily speculative. With that qualification, it provides a view of where the field came from to help understand the current state and possible future trajectories. As importantly, I offer it is as a call for more rigorous studies of the history of the field.

A further qualification is that this brief history is largely limited by the field's Euro-American perspective, which influenced the choice of areas of concentration. The field developed with heavy reliance on issues involving animals in the laboratory partially in response to the centrality of that topic in the animal protection movement in the UK and US in the 19th century. It soon also featured the study of relations with companion animals in response to the emergence of the popularity of companion animals and breed development in those countries and western Europe during that same period (Ritvo, 1987; 
Thomas, 1983). The next focus was on animals in agriculture in response to intense confinement practices that were instituted after World War II and the recognition that the numbers of such animals dwarfed those in the other two areas (Animal Rights International, 2020). An offshoot of this focus is the study of vegetarianism. More recently, in response to data on the dramatic reduction in wildlife numbers (Living Planet Report 2018, n.d.) and the "sixth great extinction" (Kolbert, 2016), studies increasingly address our relationships with wildlife, the strategy of rewilding, and human-wildlife conflict. To a significant extent, this history of shifting areas of study mirrors that of the history of the contemporary animal protection movement.

The following suggested dates are a schematic guide divided into decades as a rough organizing device.

\section{Beginnings: 1970 s}

In terms of scholarly output as distinguished from institutional presence in the academy, three individual titles are often cited as the seminal works that laid the foundation for the later emergence of HAS as a credible academic field: Singer's Animal Liberation (1973), Midgley's Beast and Man (1978), and Regan's The Case for Animal Rights (1983). All philosophers, they pushed against a highly human-centered canon. Their cases for the inclusion of animals in the moral community and, it followed, for our obligations to them provided a foundation for the emergence of the contemporary animal protection movement which, in turn, created a positive feedback loop for the further development and foci of this subfield of moral philosophy. The second and third generation of philosophers extended the seminal theories from Singer's utilitarianism, Midgley's mixed community theory, and Regan's rights theory to social contract (Rowland, 1989), eco-feminist (Gaard, 1993), and affect-based (Clough \& Halley, 2007) theories. As I will describe further, more recently, political theory is providing a shift from the philosophical issue of moral considerability to the political question of the status of different kinds of animals.

Two other works with some claim to providing the building blocks for the field are Harrison's Animal Machines (1964), which offered the first major critique of intensive confinement of animals in agriculture, and Ryder's Victims of Science (1975) for its critique of animal research and its introduction of the term "speciesism."

\section{First Wave: $1980 \mathrm{~s}$}

While philosophy provided its seminal beginnings, the first substantial wave of scholarship came from the social sciences, particularly its more quantitative 
side. Termed the "animal turn," the launch first occurred as these hard-social sciences produced empirical data that began to identify the amazing array of HAR, their benefits to humans, and their often-exploitative treatment of animals.

The founding in 1983 of the Tufts Center for Animals and Public Policy, the first HAS program, launched the institutional development of the field and gave rise, shortly thereafter, to the publication of the first devoted journal-Anthrozoös: A Multidisciplinary Journal of the Interactions of People and Animals. Given its subsequent development, both of these are interesting beginnings. The center was the brain-child of Andrew Rowan, a British-educated, South African biochemist. Its subtitle notwithstanding, Anthrozoös primarily published studies in two fields, sociology and psychology. It largely employed quantitative methods (hence "interactions" rather than "relationships"), limited itself to humancompanion animal relationships, and to an anthropocentric focus. The animal side of the relationships primarily functioned as a vehicle for human welfare, and minimal attention was given to the animals' contribution to the form of the relationships or to advocacy for animals.

Through demonstrating the sophisticated capabilities of animals, two related fields that are unapologetically animal-centered, ethology and comparative psychology, provided strong empirical bases for the study of the animal side of HAR but were not yet directly part of the field. Particularly with their emphasis on cognition ("cognitive ethology"), later they would produce studies of these capabilities in the context of HAR, such as animal worker/animal relationships.

In the latter part of this period, with the launch of Animal Welfare (1988) and the Journal of Applied Animal Welfare Science (1993), the field of animal welfare science at least implicitly contributed to the field through describing the welfare of animals inherent in our treatment of them in various settings and empirically examining refinement, reduction, and replacement alternatives ("the 3 Rs"; Russell \& Burch, 1959). Like ethology and comparative psychology, in more recent times, animal welfare science more unequivocally and directly contributes to the field through studies of the welfare implications of HAR in shelters, homes, zoos, laboratories, and the "wild."

In sum, by the end of the 8os, the scholarly side of HAS was largely centered in quantitative social science, providing an empirical foundation for the earlier developments in moral philosophy. Illustrating the first two decades, the courses developed in the field typically consisted of an introduction to the seminal ethical theories and an analysis of existing practices involving the welfare of animals, particularly in farm settings. While the institutional development side lagged behind scholarly output, these existing programs reflected 
this limited study of HAR as veterinary schools housed the first universitybased programs (e.g., Animals and Public Policy at Tufts University [Center for Animals, n.d.] and Animal Welfare Program [n.d.] at the University of British Columbia).

\section{Second Wave: 1990 s}

In response to these developments, the second wave enlarged the field to include the more qualitative social sciences, expanding the field in method, scope, and interfacing disciplines. Methodological approaches expanded to include applications of and, as was often necessary, adaptations of more qualitative and interpretative methods that allowed the study of the animal side of HAR. Examples include grounded theory, discourse analysis, symbolic interaction, participant observation, ethnomethodology, actor network theory, phenomenology, and narrative research. The scope of the field broadened beyond the emphasis on human/companion animal relationships to include the amazing array of evolved and constructed HAR. In addition to sociology and psychology, scholars in anthropology, animal law, geography, and history began to recognize and contribute to the animal turn. The publication of Society \& Animals in 1993 provided a venue for these studies.

Reflecting these trends, these and other primary disciplines interfacing with HAS offered courses that included a richer set of topics incorporating areas of interest and problematics peculiar to that discipline. An informal survey of the applicants to the best course awards project cosponsored by the Animals and Society Institute and The Humane Society of the United States shows these trends. The first award (1999) went to a course on farm animal care and welfare, while the last award given in the project (2012) featured a course in geography that "examined ethnographic, philosophical, and historical accounts of HAR, as well as theoretical essays and literary texts that demonstrate a range of cross-cultural interpretative strategies" (Garcia, 2012).

The general thrust of the qualitative and interpretative scholarship in this period was to interrogate the "social" in the social sciences. Animals are social in that they both form societies of their own and are part of human society, with the resultant inter-species societies shaped by them as well as us. These forms of relationships and the parties to them have social organization, culture, psychology, politics (power arrangements), and geography that can be examined through the relevant disciplines.

In the institutional realm during this period, in addition to single courses, there were also the beginnings of the development within arts and sciences departments of minors, concentrations, and even majors devoted to HAs. The field also expanded beyond the Anglo-American countries to Germany, 
Poland, Israel, and India. Still, at the end of this period, the field was "solid, at the margin," where the solidity was in the numbers of journals devoted to or accepting studies in HAS and the growing group of scholars world-wide, while the margin referred to the limited acceptance of the field within the academy (Shapiro, 2002a; Gerbasi, 2002; Arluke, 2002).

\section{Third Wave: 2000s}

During this period, increasingly scholars in the humanities and those employing the more interpretative approaches in the social sciences delved into theoretical issues on which the body of empirical relationships were founded. In part this emergent focus, arguably its new center of gravity, represented a shift from Anglo-American analytic philosophy to Continental traditions and their developments under the rubric of the "posts"-post-structuralism, -modernism, -colonialism, and -humanism. In what was termed "the animal question," scholars in the humanities mined the writings of Heidegger, Derrida, Foucault, and others for traces of animal-related ore (see, for examples, Deleuse \& Guattori, 1987; Agamben, 2003; Latour, 2007; Gaard, 1993; and Wolfe, 2010).

Holding that the distinction is an overdrawn if not a categorical error, studies centered on a critique of the traditional categorical distinction between human and animal being. Four moves, all forms of decentering human being, may be distinguished - raising animal being, lowering human being, blurring the distinction, and begging the question (all will be spelled out). Here it should be noted that a major part of this work is deconstructing the effect of the tradition of valorizing humans through a denigrating comparison to other animals. Some of these social constructions are reductive-taking animals as less than they are by reducing them to worldless objects, commodities, natural resources, or data points. Less commonly, the constructions are inflatinggoing beyond the general corrective that establishes animals as embodied individual subjects to taking them as humans with fur, representations, metaphors, or as mythopoetic entities (e.g., the totemic animal).

This 3 rd wave of scholarship has been met with mixed reviews. It is radical in the sense that it seeks change at the very root of our thinking about other animals. These ideological critiques demand change at the basic level of the current organization of the culture, society, and economics. However, this is often at the expense of foregoing efforts at short- and medium-term politically and economically feasible change. In some quarters, it also reinforces the perennial and often divisive tensions in the animal protection movement between welfarists and abolitionists. 
The critique of the received theory and the constructions of animals built on it opens up a space for an understanding of animals that is more accurate and respectful but largely leaves that understanding as a residual task. More critically and ironically, while seeking theoretical and conceptual clarification of the similarities and differences between human and animal being, this project can reduce consideration of the animal side of HAR. Its name notwithstanding (post-humanism), the theorizing and deconstruction is human-centered, as it deals with how humans conceived, languaged, constructed relevant institutions, and exploited animals. Beyond an abstract and generalized account, the animal side of the numerous forms of HAR remains an unfulfilled intention. As I will discuss, a challenge of the field is to develop and apply methods that deal with the problem of teasing out these complex results of our construction. A problem is to identify those aspects of the constructions that impacted the HAR from those that had little effect. As has been shown in the case of laboratory rats, the degree of influence varies. The apparent domestication of these animals over multiple generations of selective breeding and socialization in highly artificial environments did not diminish their capability, given the opportunity, of returning to the ways of the wild (Boice, 1977).

The opportunity provided by the opening and the failure to fill it was part of a general critique of the field that has been termed "the animal turn in the animal turn" (Shapiro, 2017). This was the recognition that the field heretofore had focused on the human side of HAR. Even when we include the animal as a significant part of a human-animal relationship, we may be describing our construction of the animal and not taking into account the animal's actual experience of the world and their role in the co-constitution of the relationship under study. So, it is necessary to distinguish and describe the animal-asconstructed and the animal-as-such, where the latter refers to what is left after we deconstruct and evaluate the impacts of the institutional arrangements involving them, the forms of linguistic and visual representation, and genetic manipulations. (This is a problem for method, discussed in a later section.)

Another concern about the humanities-based scholarship is that the conceptual density of its discourse is often beyond the reach of both quantitative social scientists and natural scientists. This reinforces the historical chasm between these broad areas of study (Snow, 1959) and can be a barrier to the task of scholars in the different areas working together toward a cohesive and innovative program of policy and practice. An informal survey of their respective literatures confirms this concern as evidenced by the low level of cross-references. 


\section{Fourth Wave: 2010s}

Given our closeness in time, it is difficult to obtain a bird's-eye view of developments in the field during this period. It does appear that they were complex and comprised multiple inlets joining a main stream. On the working and optimistic assumption that each provided a constructive mid-course correctiveone good turn deserving another, I organize their description as a set of "turns": the political, materialist, and affective turns. (All this "turn" talk prompted one writer to issue a warning against "turn fatigue," Grusin, 2015, pp. IX, XIX).

The political turn consisted of a number of distinct but related additions to the main stream. Adoptions and adaptations of the concepts of biopolitics and biopower from the writings of Foucault (Chrulew \& Wadiwel, 2016) and, to some extent, Agamben (2003) led to examinations of how we control, govern, and "discipline" (in Foucault's sense) animals both on individual and institutional levels.

As noted earlier, seminal theories in the 7os and their subsequent developments by later generations were based on critiques of canonical philosophical theory for its failure to include animals, except as a foil. As part of the political turn, political theorists and scientists provided complements to and extensions of these ethical theories (Anderson \& Kymlicka, 2011). Anderson and Kymlicka distinguish kinds of animals based on political categories: domesticated animals as citizen members of mixed-species communities; free living or wild animals as members of other sovereignties; liminal animals as denizens but not citizens. Their theory represents a major addition to or, perhaps more accurately, a shift from the focus on moral to political philosophy as a foundation for the field. Notably also, it is a shift from individual animals to groups - more specifically from individual capabilities to group membership. In doing so, it broaches if not at least partially breaches the wall between the animal protection and the environmental movements. A final component, criminology in effect became politicized as "green criminology" (Beirne, 2009) by arguing that the current domain of crimes should be broadened to include, for example, various practices that exploit wildlife.

Both the materialist and the affect turns (Grusin, 2015, pp. VIII, XVII) challenged the representational focus of social constructionism. As noted in the 3 rd wave, the work of deconstruction largely left as a residual task the description of animals-as-such. The new materialism took on this task and reframed it from attempts to understand their subjectivity and consciousness to descriptions featuring their performativity and physicality. Materialism refers to the corporeality of animals, the embodied nature of their interactions and relationships. However, it also includes the impact of inanimate objects - trees 
but also machines and technologies. This reframing reduces the problem of understanding HAR to the identification and description of the roles of the various actants in the relevant network. The inclusion of both animals and inanimate objects within the same frame and the concomitant discourse has both major conceptual and methodological implications. Conceptually, it strikes a blow against human exceptionalism; methodologically it side-steps the problem of the inaccessibility of the lived experience of animals.

Overlapping and reinforcing the materialist turn, the affective turn drew attention to the inter-corporeal nature of HAR by urging us to "attend to" and to empathize with the affective and sensory experiences of the other. Termed "embodied affectivity" (Fuchs \& Koch, 2014), this use of our immediate, prereflective affective sensibility opens investigators to the emotional and sensory lives of animals. Interestingly, the importance of the affective is also receiving support in the neurosciences through studies of the neural substrates of affect and emotion referenced in the recent Cambridge Declaration of Consciousness (Lowe, 2012).

Taken together, the political, materialist, and affective turns in this period buttressed the animal turn in the animal turn. They attended more to the animal-as-such and redressed the balance between emphasis on the human benefits of HAR and the costs and benefits of these relations to animals.

If only in hindsight, the sequence suggested in this wavy history makes sense. Moral philosophy raised the question of the valuing or revaluing of animals and was a major impetus to the rise of the contemporary animal protection movement. The harder social sciences provided empirical data identifying the array of human-animal relationships, their benefits to humans, and the exploitation typically involved. In response to these developments, the more interpretive social sciences and humanities delved into the issues on which these relationships rest; for beneath the ethical issues is the "question of the animal." These foundational issues call into question basic categorical distinctions, such as animal/human, nature/culture, and individual/group. Finally, in a mid-course correction, through several related turns (assuring that no stone is left unturned) the field began to give equal weight to the animal side of HAR.

\section{Celebrating the Present}

I begin this section with a brief summary of the field's achievements to date and close with an overview of the conceptual substrate of the field presented schematically in the form of four strategic moves. 
The achievements of this still youthful field are clearly a cause for celebration, as its growth has been and continues to be beyond most participants' and observers' expectations. For example, "[T] he Animals and Society Institute website lists over 300 units of study in 29 disciplines at over 200 colleges and universities, not including over 100 law school units" (O'Sullivan, Watt, \& Probyn-Rapsey, 2019, p. 363). As a number of review articles and websites provide documentation of the growth, I simply list them by major relevant categories (Table 1).

TABLE 1 Human-animal studies influence

Publication venues

- devoted journals

- individual articles in mainstream journals

- book series

- anthologies

- monographs

Presence in the academy

- courses

- concentrations

- minors

- majors

- masters' programs

- doctoral programs

- summer institutes

- research centers

Public presence

- podcasts

- policy papers

- listservs

- conferences

Many of the major university and commercial academic presses now include HAS contributions in their lists. In addition to the growth in devoted journals (Table 2), many animal-related mainstream journals now regularly include 
HAS articles (e.g., Applied Animal Behaviour Science, Animal Behaviour, Journal of Animal Science) as do mainstream journals in the many human-centered disciplines that now interface with HAS.

TABLE 2 Human-animal studies devoted journals

- Animal Law Review

- Animal Sentience

- Animal Studies

- Animalia

- Animals

- Antennae

- Anthrozoös

- Between the Species

- Human-Animal Interaction Bulletin

- Humanimalia

- Journal for Critical Animal Studies

- Journal of Animal Ethics

- Journal of Animal Law

- Journal of Animal Law and Ethics

- Journal of Animal Law and Policy

- Journal of Applied Animal Ethics Research

- Journal of Applied Animal Welfare Science

- Journal of Posthuman Studies

- Mid-Atlantic Lyceum

- Politics and Animals

- Relations: Beyond Anthropocentrism

- Sloth

- Society \& Animals

- Trace: Finnish Journal for Human-Animal Studies

Two other growth metrics were noted earlier. One is the numbers of disciplines that interface with HAS and that now have a core of scholars specializing in research at that interface-numbering 24 as of this writing (Table 3 ). 
- animal law

- anthropology

- art history

- biosemiotics

- communications

- conservation

- criminology

- cultural studies

- development studies

- education

- environmental studies

- geography

- history

- literary studies

- performance studies

- philosophy

- political theory and science

- psychology

- religion

- semiotics

- social zooarchaeology

- sociology

- urban studies

- women's and gender studies

The second is the expansion of methods to include the adaptation of those typically reserved for the study of humans and to employ qualitative and interpretative methods from the soft social sciences and the humanities. Current methods include the full range of investigative approaches, from the controlled experiment to discourse analysis (Table 4). Problematics and limitations in the area of methods will be discussed in a later section. 
- actor network theory

- archival studies

- case study

- content analysis

- controlled experiment

- dialectic method

- discourse analysis

- ethnography

- ethnomethodology

- fieldwork

- focus groups

- grounded theory

- interviews

- narrative enquiry

- participant observation

- phenomenology

- surface hermeneutics

- survey

In terms of presence in the academy, there has been significant growth in single course offerings and a smattering of new minors, majors, and programs. However, although narrowing, the lag between the production of scholarship and the development of curriculum and programs continues to be substantial. Flynn (2003) provides an account of resistance to the acceptance of a HAS course in sociology from faculty in the hard sciences. Going forward, the lag has serious implications for young scholars in HAS as they seek academic careers in the field. On the positive side, from an international perspective, institutional development is spreading beyond the US and the UK to continental Europe.

\section{Overview of Current Theory and Empirical Studies}

The task largely remains of more effectively integrating the current bodies of empirical and theoretical scholarship in the field so that they work in tandem rather than at cross-purposes. As mentioned in the history section, researchers working on the ground tracking and parsing the influences of the myriad variables contributing to HAR often have difficulty drawing testable hypotheses 
from, for them, the dense thicket of concepts flowing down from the theoreticians. In the other direction, scholars in the interpretive social sciences and the humanities are challenged to incorporate empirical relations as, for them, they have their own density, complexity, and methodological esoterica.

While a more productive mutually reinforcing two-way relationship is a work in progress, I identify four moves that frame and encompass the current state of the field. Each provides a strategy that contests and provides correctives to the received views of the categorical ontological chasm between human and animal being. Taken together, they interrogate virtually all the basic concepts in the field: relationality itself, subjectivity, agency, intersectionality, entanglement, otherness, neo-liberalism.... (See Gruen, 2018, and Animals and Society Institute Video Series, n.d., for definitions and discussions of the major concepts.) Evolving ways of conceptualizing agency provide a convenient illustration.

\section{Elevate animal being}

The first move elevates animal being to the same plane as human being through the claim that capabilities and behaviors once thought to be the exclusive province of humans are also found in some animals-for example, complex communication ("para-language") and empathy ("mirror neurons"). That some other animals have a robust agency is one example of this (McFarland \& Hediger, 2009). This finding is buttressed by empirical studies from which it can be inferred that other animals have intentionality, make plans, and anticipate the future; that they, in effect, experience their own agency, their own ability to intend to act and to affect their environment and other beings.

\section{2. "Lower" human being}

A second move consists of conducting research demonstrating that capabilities once considered limited to animals also characterize human behavior. Historically, the seminal work of Freud decentered human behavior by showing that much of our behavior is driven by and is derivative of instinct and is irrational ("unconscious"). More recently, cognitive psychology has demonstrated the irrationality of a surprising number of human behaviors-for example, selective perception ("bias"), decision-making in consumer behavior, and, a behavior with much currency politically, our treatment of others perceived to be unlike us ("outgroup," "xenophobia," "prejudice").

We also implicitly lower human being through the conceptual dilution of phenomenon once considered reserved for humans. For example, from a number of quarters of the field, the concept of agency has been reframed so that 
it includes other animals. In Latour's (2007) Actor Network Theory (ANT), an agent is reduced to an "actant," as agency no longer implies intentionality or reflection. ANT analyzes "relations which crosscut the modern 'great divide' between humans and nonhumans, subjects and objects, society and nature, in such a way that the various kinds of entities involved on both sides are treated in the same terms, which is to say, symmetrically" (Nimmo, 2011, p. 111).

The New Materialism makes a similar move. Distinguishing the "nonhuman turn" from the "nonhuman animal turn" (Grusin, 2015, pp. XX-XI), like ANT, this theory includes plants and machines as well as other animals. These re-conceptualizations of the traditional notion of agency in effect lower human being, as it is no longer the sole proprietor of agency. Part of the New Materialism or complementing it is an emphasis on corporeality and the claim by ecofeminists that HAR are profoundly embodied and multi-sensory interactions (Gaard, 1993). This also diminishes human being, as language (traditionally claimed as an exclusively human capability) is no longer necessary for the establishment and maintenance of articulate forms of connection.

\section{Blur the distinction}

This move denies the integrity of both humans and animals in the sense that each is held to be a mix of different beings (Haraway, 2007, pp. 3-160). For example, we humans have a veritable menagerie of other animals and microorganisms living in our bodies. Homo sapiens also carry a genetic heritage from other Homo species (Homo neanderthalensis). The classic definition of species as marking out a distinct and inviolable line between species is being replaced by the messier notion of hybridity. We are all in a sense chimera, and the categorical distinction between human and animal is built on shifting sand.

\section{Beg the question}

Alterity Theory, a fourth move, asserts and focuses on discontinuity or differences (Levinas, 1969). It posits an irreducible "otherness" in human-human relationships - we cannot fully know each other. Levinas then argues that this unbridgeable chasm is the basis of ethics. While he does not include other animals, the primacy Levinas gives to the face of the other- "face" in the broad sense of physiognomy or bearing - leaves an opening exploited by HAS scholars to show that other animals have a face and are properly viewed as "other." Derrida's (2008) concept of "animot" similarly emphasizes radical otherness"differance" - as the basis of respect and ethical obligation (Derrida, 1976). The concept of otherness undercuts the perennial continuity/discontinuity debate regarding humans and animals, as it contends that no other being in a 
relationship, whether human or animal, is fully knowable. This opacity or indeterminacy denies the possibility of affirming a categorical distinction between humans and animals. In HAR, as in human-human relationships, there is this distance between self and other that cannot be fully spanned and, applying the precautionary principle in ethics, requires us to respect that other.

While these four moves, and others not readily subsumable under them, all push back against human exceptionalism and the concomitant subordination of animals, on their face they offer competing and, in some instances, contrary theoretical developments. For example, lowering human being by reducing, in our example, the robustness of the concept of agency flies in the face of the empirical findings that at least some nonhuman animals demonstrate agency, empathy, and so many other sophisticated capabilities traditionally reserved "for humans only." If at the same time we argue that they are more like us and we are more like them, can we credibly dissolve the dichotomous categorization and promulgate ethics, policies, and practices that are responsible and respectful of animals? On its face, it would seem that we cannot have it both ways.

To summarize and conclude this section, there is reason to celebrate the present state of the field as it now has articulated conceptual substrates that undergird and, to an increasing extent, inform and are informed by a solid scholarly interdisciplinary base. The growing body of scholarship in the many interfacing disciplines produces a multiplying effect as more scholars are attracted to the field and the academy begins to meet their needs through the development of relevant curricula and programs. Clearly, the rate of growth of the field is accelerating and can reasonably be expected to continue to do so at least in the short- and mid-term future.

\section{Troubling the Future}

Beginning with different possible institutional homes and ending with a discussion of methodological and political futures, in this concluding section, I speculate about future trajectories of HAs. In each case, I highlight advantages and problematics - the latter as "red flags."

Possible institutional arrangements include incorporation into one or more existing disciplines, becoming a distinct and relatively independent entity within a university, and establishing a fully independent stand-alone entity outside of the academy. Another possible development is that the currently vying names of the field crystalize into one or more distinct fields. While these 
are not necessarily mutually exclusive trajectories, here I consider them separately. Of course, another possibility is that the field realize the fate of academic faddism and largely disappear from the academy or be relegated to the status of a niche area of study.

Incorporation into several disciplines is already happening as many departments have established a concentration, minor, specialty major, and/or resident fellowship. If each of the numerous interfacing fields were to include the study of HAR in their respective curricula and through the offering of subspecialties, the study might be integrated productively into the general issues of each discipline. The role of animals and HAR could be seamlessly blended into the study, much as is the case in many quarters of the studies of gender, race, and multiculturalism. Ideally, the overall effect of this would be to undercut the premise of human exceptionalism by blurring or even forgetting the humananimal divide. Particularly during the transition to these developments, it might increase the recognition and value of the study of HAR as departments see the importance of taking on board a scholar who has specialized in their study.

A number of red flags can be raised here. The assimilation of animal issues into the problematics peculiar to each discipline could undermine the interdisciplinarity that has been an important feature of HAS and one that, arguably, is inherent given its subject matter. If the ideal of universal inclusion of animal issues is not realized and, instead, its academic home is limited to a handful of disciplines, this might fractionate and compartmentalize the field. It would then take the form of a number of versions parasitic on the departments in which they reside and lose the complementarity provided by interdisciplinarity. This development would also narrow the scope of the field.

As critically, assimilation ultimately might have a regressive effect with respect to the issue of anthropocentrism. As described in the history section, HAS has made significant inroads into achieving a more balanced consideration of animals in the study of HAR. However, the field still currently occupies a marginal position in much of mainstream academia, as interest in such studies can be considered "dirty work" (Wilkie, 2015). This is readily apparent in the plight of young scholars who often face resistance to and lack of support of their HAR-related dissertation topics and who, as well, often are reluctant to be upfront about their interest in HAR as they apply for academic positions (personal communications, fellows at the ASI-UICU summer institute, 2019; also see O'Sullivan, Wyatt, \& Probyn-Rapsey, 2019).

Given the traditional relative devaluation of animals in the academy, then, the incorporation of the study of HAR might be largely in the service 
of understanding human psychology, sociology, geography, etcetera, with the animal sides of the relationships simply serving as vehicles to that end. As noted earlier, at least in its early development, the popularity of the study of animal-assisted activities in psychology, counseling, and social work clearly illustrated that risk. With this regressive form of assimilation, HAS could become fragmented and its underlying mission of valuing animals might be compromised-in effect, reinforcing the status quo treatment of animals.

Another possible institutional arrangement is that the field finds homes in relatively independent entities within a university or as freestanding research institutes. It is significant that, at present, to find examples of these we must look outside of HAS: An example of the former is Wellesley College's Wellesley Centers for Women (n.d.) and of the latter, the Sante Fe Institute (n.d.), the remit of which is the scientific studies of complexity. These have the advantages of maintaining relatively greater control over curricula, research projects, and applications to policy and practice. They also can draw faculty from many disciplines and produce robust interdisciplinary scholarship.

On the downside, given the discipline-based structure and politics of most universities, even intramural centers typically must attract their own financial support. In addition to this burden, extramural centers are in danger of becoming isolated from and devalued by mainstream scholarship. An example of this is the establishment of freestanding institutes for training in and research on psychoanalysis. While psychoanalytic thought still has some presence in university-based departments of cultural studies, literary studies, and history, the inclusion of psychoanalytic theory and practice from graduate schools that train therapists, its most natural home, has all but disappeared.

A number of developments might result from the current proliferation of contending names of the field. The presence of these many handles is a legacy of the categorical error that supported human exceptionalism, the differing views of what constitute nonexploitative forms of HAR, and the effective means of achieving the respective sought after ends.

One possibility is that the current situation persists and the field be known by a number of aliases - as befits if not an outlaw at least an outlier enterprise. While this state of affairs does produce some intra-field tension, it has allowed the attraction of scholars from the many interfacing disciplines and from political positions that vary from reformist to abolitionist means and ends (Francione \& Garner, 2010). For example, anthrozoology and critical animal studies tend to occupy different positions on the political spectrum. Arguably, part of the impressive growth of the field is this breadth and a largely constructive intra-field dialogue. However, there is the danger that that dialogue 
deteriorates into derogatory forms of competitiveness that fractionate the field and sap energy that might be channeled into genuine advances in our understanding of HAR.

Another possible development is that the currently vying names of the field crystalize into one or more distinct fields. This could be a benevolent take-over that capitalizes on the advantage of the field being known under one label without compromising the breadth of approaches and the scope of the field. However, one might become dominant, cannibalizing the others, resulting in narrowing the scope of the field and reducing its attractiveness to scholars with differing ideals and politics.

\section{Methodological Challenges}

Here I recap and expand on a number of methodological challenges that the field is facing and will face. The challenges follow from the definition of the field described in the first section: it is more challenging to study a relationship than a discrete entity, a relationship across species than within a species, and individuals of different species. It is also more difficult to develop methods that provide access to and verifiable descriptions of the experience of animals.

While resolutions to these challenges may be contained within an overriding critical investigatory stance that focuses on how we relate to and treat animals and their influence on us and the world, that approach is general and does not provide resolution to these specific hurdles. How they are overcome will be a major factor that shapes and is shaped by the forms of the institutionalization of the field, the trajectory of scholarship (e.g., the kinds of phenomena it explores and the discourse it employs), and the relation of the field to animal advocacy.

Currently, the field employs a wide range of qualitative and quantitative methods. Predominant location of the field in humanities departments and soft social science departments, or in the hard social sciences and natural sciences will entail the use of very different methods. That location also will influence the issue of balancing the treatment of the humans' and animals' contributions to the relationships under study, as the latter fields (e.g., comparative psychology, cognitive ethology, and veterinary science) have expertise in the study of animals and the former have traditionally been human-focused. Birke and Hockenhull (2012) discuss giving at least equal weighting to the animal in an anthology aptly titled Crossing Boundaries (pp. 1-15).

As a demand inherent in the field is that investigators have expertise in both the human and animal side of the relationships under study, a way to assure balance is to engage in collaborative research. A highly demanding and 
probably less efficient alternative strategy is for an individual scholar to master the literature and methods of both areas of study. Parrenas (2018), a scholar of women's studies, crossed a species boundary and through extensive and prolonged field work learned about the ethology of orangutans.

Methods of inquiry also will be differentially shaped by scholars working on either end of an empirical/theoretical spectrum. On the ground, scholars engaged in empirical, archival, and qualitative research will utilize and, where necessary, adapt existing methods in their respective interfacing disciplines. Scholars addressing theoretical issues will shape empirical methods depending on how they define "animal," "relationality," "subjectivity," and other key terms. The relative influence of empiricists and theoreticians and their interaction have important implications for methods as well as for the future trajectories of the field more broadly. For example, some methods produce results that are readily generative of applications to changes in policy and practices-others do not or are limited to changes that currently and for at least the middle-term are not politically feasible. I return to this issue in the concluding subsection on the political future of the field.

Major hurdles to adequately addressing the animal side of HAR are the pervasive social construction of animals and the questions of how to (and, in some quarters, whether it is necessary to) access their experience of the world.

The problem of how to deal with the pervasive social constructions of other animals has been framed as the relation between "animals as constructed" and "animals as such" (Shapiro, 2017). Related terminologies are the "human representations" of animals, "animal as animal" (Fudge, 2017, p. 6), "symbolic animal," and the "real animal" (Aloi, 2012, p. s89). As noted earlier, the methodological challenge here is complicated by the fact that social constructions (including genetically engineered "constructions") actually change the animals involved-often radically. In turn, this shape-shifting alters the forms of the HAR these animals co-constitute. Compare the differences in our relationships with and treatment of "lab rats," feeder rats (those used to feed other animals in the lab), and "wild" rats—-those living in the cracks and crevices of the lab (Herzog, 1988).

Once the requisite work of deconstruction is completed, we are left with the challenge of how to study the animal-as-such. A major issue is the question of whether existing methods are or can be tailor-made to be adequate for the task. Another is whether animals-as-such exist as strict social constructionists hold that it is social constructions "all the way down."

An argument for the adequacy of existing methods is that once we have (really, now that we have) evidence that individuals of many animal species 
are autonomous beings who are conscious agents of their own behavior, we can use or adapt tried and true methods from both qualitative and quantitative armamentariums for their study. In this context, Bereswill (2019) stated, "[W]e are already well equipped to do these studies" and adapting them to research on different species in different situations is not an insuperable problem. Examples of extensionist adaptations of existing methods from the humancentered disciplines that are already available include symbolic interactionism (Alger \& Alger, 1997), interspecies ethnography (Kirksey \& Helmreich, 2010), ethno-primatology (Fuentes, 2012), surface hermeneutics (Broglio, 2011), kinesthetic empathy (Shapiro, 1990), and empathic imagination (Malamud, quoted in Copeland, 2012, p. s99).

Technological advances also are likely to continue to play a major role in providing innovative methods. Sophisticated technology will give us more access to both sides of the HAR. In vivo brain scans allow monitoring neurological changes in fully conscious animals and humans. Machine learning tools can identify emotions such as joy, fear, and pain in mice (Dolensek, Gehrlach, Klein, \& Gogolla, 2020).

On the other side, there are arguments that access to an animal's experience of the world is not possible, only exists as an emergent property of being in relationships, and, in any case, is not really critical to understanding HAR. Nagel's (1974) oft-quoted paper, "What is it to be a bat?" (1974) and Wittgenstein's aphorism, "if a lion could talk, we would not understand him," (quoted in Wolfe, 2003, p. 1) have raised the epistemological question - are animals knowable? Both of these scholars do not so much deny the existence of subjectivity in animals as point to the methodological barriers to accessing it. This leaves open the question of whether existing methods, even as adapted, are suitable tools or if we will need to develop suigeneris methods.

As implied earlier, a number of theories cast doubt on the importance of describing the subjective life of animals. Taken together, Latour's ANT (2007) and the New Materialism (Grusin, 2015) exempt agency from the requirement of intentionality and reflection and, as well, include plants and machines as formative components of relationships. This has strong implications for methods, as the entities in a relationship need not be conscious beings. The subjective lives of those actants that have such can be inferred from direct study of the physicality, corporeality, and performativity of their interactions. In these theories, consciousness is not somehow housed in the individual but rather arises in relationships - and, therefore, can only be observed in interactions. The "between" is all there is or, at least, is all that needs to be studied. There is no residual consciousness: “[A]nimal 'mind,' or the meaning of animal behavior, 
is not hidden somewhere inside the animal but is co-constructed relationally in interspecies interaction" (Nimmo, 2012, p. 184).

By exempting agency from intentionality and reflection, and by including plants and machines as components of relationships under study, the thrust of these theories is to downgrade the importance of explicating the subjective lives of those members of a network that have some claim to being conscious beings. It is worth recalling in this debate that as the field is defined, the animal-as-such or the real animal is a means to the end of understanding HAR. The contributions of the hard sciences and of the soft social sciences and humanities may be sufficient given that end - the former through behavioral analysis or through functional explanations that guide, respectively, the acquisition of and evolution of behaviors, and the latter through performative and qualitative approaches that dwell in or interact within an animal's umwelt (von Uexkull, 1934/1957).

As befits a discussion of future developments, we are left with more questions than answers. Can we rely on methods already available in the social sciences and the animal-related natural sciences to understand human-animal relationships, or do we require the development of sui generis approaches? What is left, if anything, of the animal-as-such once the layers of social construction are revealed? Can the theoretical and the empirical work together or will the perennial divide between the "two cultures" (Snow, 1959) be an insuperable barrier? If collaboration needs to be the order of the day, can, for example, philosophers and ethologists work together effectively? If interdisciplinarity is requisite, can it overcome the traditional discipline-based structure, economics, and politics of universities? Can the field produce recommendations for both short- and long-term socially and politically acceptable changes to policies and practices? I turn now to a discussion of this last question.

\section{Political Challenges}

I have discussed "politics" within the field and its relations to other fields. Here we move from the politics within the academic world to politics at large.

An initial issue is the appropriate role of scholars as advocates. Can, should, and will scholars use their scholarship as a platform for changes in our relations to and treatment of animals, and how will it be accepted both within the university and by the public? Although the field has achieved some credibility, there is hesitancy in some quarters to adopt a hybrid scholar-advocate role (Copeland, 2012, s98). Particularly in the hard sciences, scholars are reluctant to adopt even the most indirect appearance of being an advocate due to the regulative ideal in those disciplines of objectivity and its claim to value 
neutrality. However, most HAS scholars do self-identify as scholar-advocates (Shapiro \& Green, unpublished survey). The currency of the ideas of engaged scholarship and effective advocacy also signal the acceptance of and, really, the demand for their input.

Beyond after-hours activism, scholars assuming a robust scholar-advocate role can frame their research programs (and their course syllabi) in response to current policy and practice issues and, proactively, to issues on the horizon. Research that supports modest on-the-ground reductions in the exploitation of animals could work in concert with research that questions assumptions underlying deep attitudes about the status and role of animals in human society. Scholars can then disseminate policy and practice recommendations directly to the public or through the intermediary of the political arms of animal protection organizations. It is generally now accepted and expected by the media and the courts that experts present their findings and their policy implications.

The recent advent of political theory that includes the status of different kinds of animals in society might facilitate a realistic and productive scholarship/policy interface that might include more foundational cultural change in the ways we relate to other animals. As it addresses forms of oppression across social justice movements, the focus on intersectionality, the idea of linked oppressions developed in feminism and then extended to eco-feminism, may also provide an impetus to addressing policy issues.

However, a number of cautionary tales should be told. The effectiveness of research as a driver of progressive and politically realistic policy may be limited. As has been the case for scholarship that complements other social justice movements (e.g., gender and women's studies), there is the danger that apparently relevant scholarship becomes insular and inaccessible, while creating its own set of self-sustaining agendas without regard for policy needs. While some of the HAS scholarship, particularly within the humanities, will continue to provide needed reexamination of foundational issues regarding the status society gives to animals, the conceptual depths of these inquiries risk its discourse becoming esoteric and in-grown, resulting in its irrelevance to long-term cultural change. I note here that humanities scholars greatly outnumbered natural and hard social scientists at the summer institute referred to earlier. This predominance of conceptual analysis may reduce the production of the kind of quantitative empirical data that, at least currently, has a greater impact on policy and practice. In this scenario, HAS becomes elitist and self-nourishing. Walled up in the ivy vines of the academy, reciprocal intercourse with policy stake-holders is greatly reduced. 
On the other hand, if this isolation is avoided, the influence of scholarship has the two-headed risks of reinforcing the received view of humancenteredness and of offering unreachable (if desirable) radical change. These two possibilities mirror the perennial tension within the animal protection movement between reformism and abolitionism. Such tension is not unique to this social justice movement. As Wuerthner, Crist, and Butler (2014) note, "Within every social change movement there are tensions between reformers and those who seek structural change" (p. XIII). Within HAS a comparable tension exists between scholars working under the respective banners of anthrozoology and critical animal studies. The former could buttress the by now regressive view that animals are primarily resources for human needs; the latter risks a radicalization of the field beyond even medium-term practical adoption of its findings. While within the academy the critique of neo-liberalism and corporate capitalism is commonplace, beyond its confines a global shift to the right has fostered the establishment of a number of authoritarian leaders of powerful countries. Under their regimes, dissenters are scapegoated, excluded from participation in political discourse, and tarred with the brush of terrorism (viz., in the US, the Animal Enterprise Terrorism Act, 2006).

The current political reality is that gradualist policy advances, particularly those that are consistent with economic growth (viz., Pacelle's, 2016, "humane economy"), will have the most purchase. This is not to say that we should not be pursuing foundational research that informs our choice of studies and that provides rationale for more radical systemic change. Rather than scaring off policy-makers, such calls might have a radical flank effect that provides bargaining power for more moderate advances. However, the current reality is that funding for such research is difficult to obtain.

Another possibility is that technological advances such as the development of in vitro or cultured meat might provide means that make radical change politically and economically possible.

In addition to scholarship supporting and positively interacting with the animal protection movement, collaborations with scholars who form the academic base of other social justice movements present further opportunities for increasing the legitimacy and influence of HAs. An alliance with environmental studies would seem a natural one, as both are concerned with the well-being of animals. Recent studies demonstrating the dramatic decline in wildlife (Living Planet Report 2018, n.d.) might provide an incentive to resolve or at least put aside the on-again/off-again claims of incompatibility based on environmentalists' focus on populations and animal protectionists' focus on individual animals (Hargrove, 1992; viz., the program at New York University: NYU Animal Studies, n.d.). 
The COVID-19 epidemic dramatically and tragically illustrates the need for social justice movements and their respective scholarly counterparts to work together. The likely zoonotic origins of the virus and factors leading to its becoming a pandemic implicate environmental (e.g., human consumption of wild animals, illegal wildlife trade), animal protection (e.g., live animal markets and industrialized animal agriculture), and racial issues (e.g., its disproportionate incidence in minority populations) (Argent, 2020).

The concept of intersectionality provides a conceptual frame for a working relation across the fields and could be to the advantage of all. Again, these cross-over effects could dilute the mission of animal protectionism if it is subordinated to human-based oppressions.

The growing popularity of the one-health movement may play a role in the future of HAS. The movement is predicated on the view that most diseases have roots in the relationships of humans and animals. Its mission is to create alliances across human, animal, and environmental health sectors (Deem, Lane-deGraaf, \& Rayhel, 2019). Trans-species psychology, a subfield of psychology, has a related remit (Bradshaw, 20o9). Like the broader one-health movement, it explores the bi-directionality of the causes and treatments of diseases, including behavioral disorders. A concern here it that the focus of these movements on pathology may reframe HAs largely in terms of pathology-if you will, pathologizing the field and centering it in veterinary science and medicine. An emphasis on the phenomenon of zoonosis, particularly given the zoonotic origin of the CoviD-19 pandemic, makes the impact of their development of HAS and on policy indeterminate. For example, as bats are a lead suspect providing the vector that led to the pandemic, will we invest in finding solutions to the white-nose syndrome afflicting bats world-wide or welcome the reduction in their populations?

\section{Concluding Remarks}

In place of a summary, I end this paper with an open-ended invitation to scholars and other stake-holders to weigh in. Comments will be considered for publication in a forthcoming issue of the journal. While I tried to stay with a close reading of this now very extensive field, this is inevitably a personal account. I reiterate that my bottom-line criterion for success of the field is its contribution to the betterment of HAR and the lives of both humans and animals. I am an independent scholar and animal advocate who has worked to advance scholarship to that end. My own scholarship (phenomenological psychology) is peripheral both to mainstream social sciences and to the humanities. My 
hope is that this marginality has provided me with critical distance from both areas of scholarship.

Given the 6th great extinction, global warming, and ocean pollution, our obligation to animals has never been timelier and more compelling. One recent study found a reduction of $65 \%$ of land-based wildlife in the past 40 years (Living Animal Report 2018, n.d.), while another found that the body mass of humans and domesticated animals now greatly exceeds that of wild animals ("biological proportionality"; Kalahari Lion Research, 2015). In the not-toodistant past, the herds of bison extended to the horizon, the seas teemed with whales and turtles, and the flights of passenger pigeons were as clouds in the sky. In their place, chickens that never see the light of day outnumber all birds of other species combined.

In Berger's seminal 1977 essay (reprinted in About Looking, 1980), he deplored the disappearance of animals from our daily lives. According to Berger, the animals' sides of HAR have been reduced to "signs," "symbols," representations, and abstractions. We know and relate to animals as images, pictures, decorations, and toys. Our companion animals are as "human puppets" (p. 15), while animals in zoos are as pictures in an art gallery (p. 23) - "spectacles" that we look at but cannot look, or have lost the interest in looking, at us. In Derrida's (1976) term, actual fully present animals are "under erasure" and we are left with animals that are only present as absent.

Aside from domesticated animals, will our future relationships with animals in the wild be largely through Nature and National Geographic programs where their only voice is that of the omnipresent David Attenborough? Will the irony be that we know more about animals and HAR than ever was imaginable but those relationships are largely memories and products of our imagination? Will our relationships with animals take the form in which they are present only as the animals that once shared the earth with us?

The emergence and development of HAS over the last four decades is beyond expectation - surely, at least that cup runneth over. We then have the burden and opportunity to use our knowledge to assure the continued and expanding plethora of relationships with them for their, our, and the planet's sake.

\section{References}

Agamben, G. (2003). The open: Man and animal. Stanford: Stanford University.

Alger, J., \& Alger, S. (1997). Beyond Mead: Symbolic interaction between humans and felines. Society \& Animals, 5(1), 65-81. 
Aloi, G. (2012). Deconstructing the animal in the search for the real. Anthrozoös, 25 (Supplement), S73-S9o.

Anderson, S., \& Kymlicka, W. (2011). Zoopolis: A political theory of animal rights. Oxford: Oxford University.

Animal Enterprise Terrorism Act. (2006, November 27). Retrieved from https://www .congress.gov/109/plaws/publ374/PLAW-109publ374.pdf.

Animal Rights International. (2020). The farm animal campaigns. Retrieved from https://web.archive.org/web/20080224045229/http://www.ari-online.org/.

Animal Welfare Program. (n.d.). Retrieved from https://awp.landfood.ubc.ca/about/.

Animals and Society Institute Video Series. (n.d.). Retrieved from https://www.animal sandsociety.org/human-animal-studies/defining-human-animal-studies-an-asi -video-project/.

Argent, G. (2020, May). Covid-19 update: The pandemic's toll on humans and animals. Animals and Society Institute: HAS Report.

Arluke, A. (2002). A sociology of sociological animal studies. Society \& Animals, 10(4), 369-374.

Beirne, P. (2009). Confronting animal abuse_Law, criminology, and human-animal relationships. New York: Rowman and Littlefield.

Bereswill, M. (2019). Meeting in the contact zone: The interactive co-constitution and power relations of interspecies relationality. Paper presented at European Summer School "Interspecies Relationality," University of Kassel, Germany.

Berger, J. (1980). Why look at animals? In About looking. New York: Pantheon.

Birke, L., \& Hockenhull, J. (2012). Crossing boundaries: Investigating human-animal relationships. Leiden: Brill Academic.

Boice, R. (1977). Burrows of wild and albino rats: Effects of domestication, outdoor raising, age, experience, and maternal state. Journal of Comparative Physiological Psychology, 91, 649-661.

Bradshaw, G. (2009). Elephants on the edge. New Haven: Yale University Press.

Broglio, R. (2011). Surface encounters: Thinking with animals and art. Minneapolis: University of Minnesota.

Center for Animals and Public Policy, Tufts University. (n.d.). Retrieved from https:// vet.tufts.edu/center-for-animals-and-public-policy/about-the-center/.

Centers for Women, Wellesley College. (n.d.). Retrieved from https://www.wcwonline .org/.

Chrulew, M., \& Wadiwel, D. (2016). Foucault and animals. Leiden: Brill Academic.

Clough, P.T., \& Halley, J. (2007). The affective turn: Theorizing the social. Durham, NC: Duke University.

Copeland, M. (2012). Literary animal studies in 2012: Where we are, where we are going. Anthrozoös, 25(Supplement), S91-S105. 
Deem, S.L., Lane-deGraaf, K.E., \& Rayhel, E.A. (2019). Introduction to one health: An interdisciplinary approach to planetary health (1st ed.). John Wiley \& Sons, Inc.

Deleuze, G., \& Guattari, F. (1987). A thousand plateaus: Capitalism and schizophrenia. Minneapolis: University of Minnesota.

DeMello, M. (Ed.). (2010). Teaching the animal: Human-animal studies across the disciplines. New York: Lantern.

Derrida, J. (1976). Of grammatology (Trans. G.C. Spivak). Baltimore: John Hopkins University Press.

Derrida, J. (2008). The animal that therefore I am: More to follow. New York: Fordham University Press.

Dhont, K., Hodson, G., Loughnan, S., \& Amiot, C. (2019). Rethinking human-animal relations: The critical role of social psychology. Group Processes and Intergroup Relations, 22(6), 769-784.

Dolensek, N., Gehrlach, D.A., Klein, A.S., \& Gogolla, N. (2020, April 3). Facial expressions of emotion states and their neuronal correlates in mice. Science, 368(6486), 89-94.

EarthSky. (2011, August 25). New census: We share Earth with millions of species. Retrieved from https://earthsky.org/earth/new-census-we-share-earth-with-mil lions-of-unknown-species.

Echeverri, A., Karp, D., Naidoo, R., Zhao, J., \& Chan, K. (2018). Approaching humananimal relationships from multiple angles: A synthetic perspective. Biological Conservation, 224, 50-62.

Flynn, C. (2003). A course is a course, of course, of course (unless it's an animals and society course): Challenging boundaries in academia. International Journal of Sociology and Social Policy, 23(3), 94-106.

Francione, G., \& Garner, R. (2010). The animal rights debate: Abolition or regulation? New York: Columbia University.

Fuchs, T., \& Koch, S. (2014). Embodied affectivity: On moving and being moved. Frontiers in Psychology, 5, 508.

Fudge, E. (2017). What was it like to be a cow: History and animal studies. The Oxford Handbook of Animal Studies (L. Kalof, Ed.). Oxford: Oxford University.

Fuentes, A. (2012). Human-primate interface. Annual Review of Anthropology, 41, 101-117.

Gaard, G. (Ed.). (1993). Ecofeminism: Women, animals, nature. Philadelphia: Temple University Press.

Garcia, M. (2012). Transnational guinea pigs: Animals, development, and culinary ethics in Peru. Unpublished.

Gerbasi, K. (2002). The "furry ceiling": Clinical psychology and animal studies. Society \& Animals, $10,353-360$. 
Glenk, L., Kothgassner, O., Stetina, B., Palme, R., Kepplinger, B., \& Baran, H. (2014). Salivary cortisol and behavior in therapy dogs during animal-assisted interventions: A pilot study.Journal of Veterinary Behavior, 9, 98-106.

Gruen, L. (Ed.). (2018). Critical terms for animal studies. Chicago: University of Chicago. Grusin, R. (Ed.). (2015). The nonhuman turn. Minneapolis: University of Minnesota.

Hamilton, L., \& Taylor, N. (2017). Ethnography after humanism: Power, politics, and method in multi-species ethnography. New York: Palgrave.

Haraway, D. (2007). When species meet. Minneapolis: University of Minnesota Press.

Hargrove, E. (Ed.). (1992). The animal rights/environmental ethics debate: The environmental perspective. Albany: State University of New York Press.

Harrison, R. (1964). Animal machines. London: Vincent Stuart.

Herzog, H. (1988). Moral status of mice. American Psychologist, 43(6), 473-474.

Kalahari Lion Research. (2015, January 16). Retrieved from http://www.kalaharilionresearch.org/2015/o1/16/human-vs-livestock-vs-wild-mammal-biomass-earth/.

Kemmerer, L. (2006). Verbal activism: 'Anymal'. Society \& Animals, 14(1), 9-15.

Kirksey, S., \& Helmreich, S. (2010). The emergence of multispecies ethnography. Cultural Anthropology, 25(4), 545-576.

Kolbert, E. (2016). The sixth extinction: An unnatural history. New York: Picador.

Kopnina, H. (2017). Beyond multispecies ethnography: Engaging with violence and animal rights in anthropology. Critique of Anthropology, 37, 1-25.

Latour, B. (2007). Reassembling the social: An introduction to actor-network theory. Oxford, UK: Oxford University.

Levinas, E. (1969). Totality and infinity (Trans. A. Lingis). Pittsburgh: Duquesne University.

Lin, P. (2016, February 1). Relationships with robots. Retrieved from https://www.forbes .com/sites/patricklin/2016/o2/o1/relationships-with-robots-good-or-bad-for -humans/\#33cdf26c7adc.

Living Animal Report 2018. (n.d.). Retrieved from https://www.worldwildlife.org/ pages/living-planet-report-2018.

Low, P. (2012). The Cambridge Declaration on Consciousness. Retrieved from http:// fcmconference.org/img/Cambridge.

Marino, L. (2012). Construct validity of animal-assisted therapy and activities: How important is the animal in AAT? Anthrozoös, 25(Supplement), s139-s151.

Marvin, G., \& McHugh, S. (Eds.). (2014). Routledge handbook of human-animal studies. New York: Routledge.

McCance, D. (2012). Critical animal studies: An introduction. Albany: SUNY.

McFarland, S., \& Hediger, R. (2009). Animals and agency: An interdisciplinary exploration. Leiden: Brill Academic. 
Midgley, M. (1978). Beast and man: The roots of human nature. Ithaca, NY: Cornell University Press.

Nagel, T. (1974). What is it to be a bat? Philosophical Review, 83, 435-450.

Nimmo, R. (2011). Actor-network theory and methodology: Social research in a morethan-human world. Methodological Innovations Online, 6, 108-119.

Nimmo, R. (2012). Animal cultures, subjectivity, and knowledge: Symmetrical reflections beyond the great divide. Society \& Animals, 20, 173-192.

NYU Animal Studies. (n.d.). https://as.nyu.edu/content/nyu-as/as/departments/environment/animal-studies.html.

O'Sullivan, S., Wyatt, Y., \& Probyn-Rapsey, F. (2019). Tainted love: The trials and tribulations of a career in Animal Studies. Society \& Animals, 27(4), 361-382.

Pacelle, W. (2016). The humane economy: How innovators and enlightened consumers are transforming the lives of animals. New York: William Morrow.

Parrenas, J. (2018). Decolonizing extinction: The work of care in orangutan rehabilitation. Durham: Duke University Press.

Podberscek, A. (Ed.). (2012). Anthrozoös, 25(Supplement), S5-S189.

Regan, T. (1983). The case for animal rights. Berkeley: University of California Press.

Ritvo, H. (1987). The animal estate: The English and other creatures in the Victorian Age. Cambridge, MA: Harvard University Press.

Rowland, M. (1998). Animal rights: A philosophical defence. London: Macmillan.

Russell, W., \& Burch, R. (1959/1992). Principles of humane experimental technique. London: Universities Federation for Animal Welfare.

Ryder, R. (1975). Victims of science. London: Davis Poytner.

Santa Fe Institute. (n.d.). Retrieved from https://www.santafe.edu/.

Shapiro, K. (1990). Understanding dogs through kinesthetic empathy, social construction, and history. Anthrozoös, 3(3), 184-195.

Shapiro, K. (2002a). Editor's introduction: The state of human-animal studies: Solid, at the margin. Society \& Animals, 10(4), 331-338.

Shapiro, K. (Ed.). (2002b). The state of human-animal studies. Society \& Animals, 1o(4), 330-442.

Shapiro, K. (2017). The History and Future of Human-Animal Studies. Paper presented at the University of Illinois, Champagne-Urbana.

Shapiro, K. (2019). Human-Animal Studies: Remembering the Past, Celebrating the Present, Troubling the Future. Paper presented at the University of Western Cape, Cape Town, South Africa.

Shapiro, K., \& DeMello, M. (2010). The state of human-animal studies. Society \& Animals, 18, 307-318.

Singer, P. (1975). Animal liberation. New York: Avon Books.

Snow, C. (1959). The two cultures. London: Cambridge University. 
South, N., \& Beirne, P. (1998). Editors' introduction. Theoretical Criminology, 2, 147-148. Taylor, N. (2013). Humans, animals, and society: An introduction to human-animal studies. New York: Lantern.

Thomas, K. (1983). Man and the natural world. New York: Pantheon.

Von Uexkull, J. (1934/1957). A stroll through the world of animals and men. In C. Schiller (Ed.), Instinctive behavior (pp. 5-83). New York: International Universities Press.

Waldau, P. (2013). Animal studies: An introduction. Oxford: Oxford University.

Wilkie, R. (2015). Academic "dirty work": Mapping scholarly labor in a mixed-species field. Society \& Animals, 23(3), 211-230.

Wittgenstein, L. (2001/1951). Philosophical investigations (G. Anscombe Trans.). New York: Macmillan.

Wolfe, C. (2003). In the shadow of Wittgenstein's lion. In C. Wolfe (Ed.), Zoontologies: The question of the animal. Minneapolis: University of Minnesota.

Wolfe, C. (2010). What is posthumanism? Minneapolis: University of Minnesota Press.

Wuerthner, G., Crist, E., \& Butler, T. (Eds.). (2014). Keeping the wild: Against the domestication of the earth. Washington, DC: Island Press. 